\title{
ANALISIS FAKTOR-FAKTOR YANG MEMENGARUHI PEMBELIAN IMPULSIF PADA PENGGUNA APLIKASI SHOPEE
}

\author{
Merry Cynthia ${ }^{1}$ \\ Djajasukma Tjahjadi ${ }^{2}$ \\ Ekabrata Yudhistira \\ ${ }^{1,2,3}$ Sekolah Tinggi Manajemen Informatika dan Komputer LIKMI \\ Jl. Ir. H. Juanda no 96 Bandung \\ merrycynthia15@gmail.com ${ }^{1}$,djaja@likmi.ac.id ${ }^{2}$
}

\begin{abstract}
ABSTRAK
Pekembangan teknologi yang sangat cepat sekarang ini sangat berpengaruh terhadap kehidupan khususnya dalam upaya pemenuhan kebutuhan hidup. Salah satu aplikasi yang memanfaatkan teknologi untuk e-commerce yaitu Shopee. Penelitian ini dilakukan guna mengetahui seberapa besar pengaruh promosi, kualitas informasi, electronic word of mouth, online store belief's, persepsi harga, dan motivasi belanja hedonis terhadap pembelian impulsif pengguna. Penelitian ini dilakukan kepada 290 responden dan menggunakan model analisis regresi linear berganda

Pada penelitian ini diketahui bahwa persepsi harga dan motivasi belanja hedonis berpengaruh terhadap pembelian impulsif pengguna, tetapi promosi, kualitas informasi, electronic word of mouth, online store belief's tidak berpengaruh terhadap pembelian impulsif pengguna. Pada penelitian ini menggunakan gender sebagai pemoderasi dan diperoleh hasil pada responden pria kualitas informasi dan persepsi harga berpengaruh terhadap pembelian impulsif sedangkan pada responden wanita online store belief's dan motivasi belanja hedonis berpengaruh terhadap pembelian impulsif.
\end{abstract}

Kata kunci : Promosi, Kualitas Informasi, Electronic Word of Mouth, Online Store Beliefs, Persepsi Harga, Motivasi Belanja Hedonis, Pembelian Impulsif

\begin{abstract}
The rapid development of technology today is very influential on life, especially to meet the needs of life. One application that uses technology for e-commerce is Shopee. This study was conducted to determine how much influence promotion, information quality, electronic word of mouth, online store beliefs, price perceptions, and hedonic shopping motivations have on users' impulsive purchases. This research was conducted on 290 respondents and used a multiple linear regression analysis model.

This study, it is shown that price perception and hedonic shopping motivation affect users' impulse buying, but promotion, information quality, electronic word of mouth, online store beliefs have no effect on users' impulsive purchases. This study using gender as a moderator and the results obtained in male respondents that the quality of information and price perceptions affect impulse buying, while in female respondents online store beliefs and hedonic shopping motivation affect impulse buying.
\end{abstract}

Keyword : Promotion, Information Quality, Electronic Word of Mouth, Online Store Beliefs, Price Perception, Hedonic Shopping Motivation, Impulsive Buying 


\section{PENDAHULUAN}

Berbagai macam transaksi jual beli saat ini dapat dilakukan secara online menggantikan transaksi yang dilakukan secara konvensional. Kegiatan ini terjadi karena dorongan pertumbuhan teknologi dan juga dorongan akibat pandemi Covid-19 yang mendukung kegiatan jual beli secara online. Pada platform Shopee menyediakan berbagai macam kebutuhan masyarakat secara lengkap mulai dari makanan, pakaian, perkakas, obat-obatan, dan masih banyak lainnya.

Dengan adanya kemajuan teknologi yang pesat memudahkan masyarakat untuk mengakses berbagai macam informasi dan mendapat kemudahan untuk melakukan berbagai macam transaksi. Hal ini mengakibatkan perilaku pembelian impulsif sering kali terjadi. Pembelian impulsif merupakan pembelian yang dilakukan tidak seperti pembelian yang direncanakan, pembelian ini terjadi secara spontan dan pembeliannya terjadi saat seorang melihat suatu barang dan secara tiba-tiba ingin membeli barang tersebut, dan langsung melakukan transaksi pembelian pada saat itu juga[2]. Terdapat beberapa faktor yang mendorong terjadinya pembelian impulsif seperti promosi, kualitas informasi, electronic word of mouth, online store belief's, persepsi harga, dan motivasi belanja hedonis. Penelitian ini mengkaji pegaruh masing - masing faktor terhadap pembelian impulsif yang terjadi pada gender pria dan wanita pengguna aplikasi Shopee.

\section{STUDI LITERATUR}

Berikut adalah berbagai teori dan konsep mengenai variabel-variabel yang dapat mempengaruhi pembelian impulsif yang digunakan dalam penelitian ini :

a. Promosi

Suatu kegiatan untuk berkomunikasi atau menyampaikan informasi antara penjual dengan pembeli yang bersifat menyebarkan informasi, membujuk, memengaruhi, dan meningatkan pasar sasaran dengan tujuan guna menciptakan permintaan produk barang atau jasa yang ditawarkan oleh perusahaan merupakan promosi. [1]

Promosi dapat memikat perhatian pelanggan lama maupun pelanggan baru sehingga akan meningkatkan pembelian yang terjadi secara impulsif. Maka dapat dikatakan semakin sering dilakukan promosi maka tingkat terjadinya pembelian secara impulsif akan meningkat. Menurut paparan tersebut dapat diajukan hipotesis bahwa promosi berpengaruh pada pembelian impulsif.

b. Kualitas informasi

Kualitas informasi merpakan hal penting untuk membuat para pemangku kepentingan membuat suatu penilaian kinerja yang masuk akal juga mengambil keputusan yang tepat.[5]

Kualitas informasi yang baik dapat memengaruhi seseorang untuk melakukan pembelian impulsif. Dalam hal ini berarti semakin tinggi kualitas informasi yang tepat waktu, relevan, akurat, dan lengkap maka semakin tinggi pembelian impulsif yang dilakukan. Menurut paparan tersebut dapat diajukan hipotesis bahwa kualitas informasi berpengaruh pada pembelian impulsif

c. Electronic word of mouth

E-Wom mengacu pada pernyataan apapun yang didasarkan pada pengalaman positif, netral, atau negatif yang dibuat oleh calon pembeli, aktual atau mantan pembeli mengenai produk, merek, layanan atau perusahaan yang ada untuk banyak orang dan lembaga melalui internet.[6]

Ketika seseorang membaca komentar atau testimoni, secara tidak langsung pikiran dan sikap orang tersebut dipengaruhi oleh komentar yang diunggah di sosial media atau platform tertentu. Sehingga dapat dikatakan semakin tinggi Electronic Word- 
Of-Mouth maka semakin tinggi pula pembelian impulsif. Menurut paparan tersebut, dapat diajukan hipotesis bahwa electronic word of mouth berpengaruh terhadap pembelian impulsif

d. Online store belief's

Kepercayaan online adalah elemen dasar yang penting untuk membangun hubungan yang baik dengan pelanggan.[7]

Kepercayaan yang tercipta bisa menimbulkan efek emosi (positive affect) bagi pembeli. Kepercayaan toko online mengakibatkan pembeli menjadi percaya bahwa toko online akan memberi respon yang baik selama proses transaksi sesuai dengan yang dijanjikan. Oleh sebab itu dapat dikatakan bahwa kepercayaan adalah sesuatu yang penting yang perlu dibangkitkan pada sebuah perusahaan atau vendor. Semakin tinggi tingkat kepercayaan yang dipunyai konsumen maka konsumen akan menjurus untuk berbelanja tanpa memedulikan resiko yang dapat terjadi dalam belanja secara online. Menurut penjelasan tersebut, dapat diajukan hipotesis bahwa online store belief's berpengaruh pada pembelian impulsif.

e. Persepsi Harga

Harga digunakan sebagai indikator nilai bilamana harga dihubungkan dengan manfaat yang dirasakan terhadap suatu jasa atau barang. [3]

Harga merupakan faktor utama bagi pelanggan agar tertarik melakukan pembelian. Apabila harga dari suatu produk bisa dijangkau oleh konsumen maka produk tersebut akan lebih mudah mendapat perhatian dan diterima konsumen. Harga yang terlihat mencolok dan menarik dapat memengaruhi perilaku konsumen dalam pembelian tidak terencana. Hal ini dapat meningkatkan pembelian yang tidak direncanakan. Menurut paparan tersebut, dapat diajukan hipotesis bahwa persepsi harga berpengaruh pada pembelian impulsif

f. Motivasi belanja hedonis Pembelanjaan hedonis merupakan suatu cara untuk mendapatkan hiburan dan pengalaman yang baru. [4]

Pada saat pelanggan mendapati motivasi belanja hedonis, pelanggan tersebut tidak akan mempertimbangkan manfaat dan nilai dari suatu barang yang akan dibeli. Oleh sebab itu itu dapat disimpulkan bahwa semakin tinggi motivasi belanja hedonis seseorang maka terjadinya pembelian impulsif akan semakin meningkat. Menurut paparan tersebut, dapat diajukan hipotesis bahwa motivasi belanja hedonis berpengaruh pada pembelian impulsive.

Berdasarkan penjelasan hipotesis di atas, model konseptual penelitian ditampilkan seperti pada Gambar 1. 
Promosi (x1)

1. Memberikan kupon

2. Jaminan garansi produk

3. Hadiah

4. Potongan harga (diskon)

(Suyanto , 2003:117)

Kualitas Informasi (x2)

1. Akurasi

2. Ease of understanding

3. Dipercaya

4. Bermanfaat

5. Lengkap

(Hamidi, 2017:1-7)

\section{E-WOM (x3)}

1. WOM Intensity

2. Opinion Valance

3. Content

(Sugianto, 2016:3)

Online Store Beliefs (x4)

1. Benevolence

2. Competence

3. Integrity

4. Predictability

(Lee, 2013 : 169)

Persepsi Harga (x5)

1. Daya saing harga

2. Kesesuaian harga dengan kualitas produk

3. Kesesuaian harga dengan manfaat

4. Keterjangkauan harga (Harsanto, 2017)

Gambar 1

Model Penelitian 


\section{METODE PENELITIAN}

Metode penelitian kuantitatif merupakan metode penelitian yang berlandaskan pada filsafat positivisme, digunakan untuk meniliti pada populasi atau sampel tertentu. Teknik pengambilan sampel pada umumnya dilakukan secara random, pengumupulan data menggunakan instrument penelitiann, analisis data bersifat kuantitatif atau statistic dengan tujuan untuk menguji hipotesis yang telah ditetapkan.[8]

a. Teknik pengambilan sampel yang dipakai untuk mengambil data adalah teknik nonprobability sampling, teknik nonprobability sampling tidak memiliki peluang yang sama bagi setiap anggota populasi untuk ditunjuk menjadi sampel. Penulis memilih sampling purposive sebagai cara memilih sampel dengan pertimbangan tertentu. Pertimbangan sampel ini adalah sampel yang memang merupakan pengguna Shopee, karena pengguna Shopee dinilai dapat memberikan informasi yang sesuai dengan masalah yang diteliti oleh penulis.

Penentuan jumlah sampel yang digunakan tergantung dari jumlah indikator $\mathrm{x}$ faktor pengali yaitu 5 - 10. Total jumlah indikator dalam penelitian ini yaitu sebanyak 30 indikator. Maka perhitungannya adalah 29 indikator x $10=290$, artinya peneliti membagikan kuesioner kepada 290 responden.

b. Jenis data yang dikumpulkan dalam penelitian ini adalah data primer dan data sekunder. Data primer adalah data yang diambil langsung yang dapat berupa jawaban responden dengan cara membagikan kuesioner pertanyaan menggunakan google form. Sedangkan data sekunder adalah data yang diperoleh melalui informasi dari peneliti terdahulu yang ada relefansinya dengan penelitian ini.

\section{HASIL DAN PEMBAHASAN}

a. Uji T (Uji Parsial)

Uji T perlu dilakukan karena Uji T digunakan untuk menganalisis pengaruh variabel bebas yaitu promosi, kualitas informasi, electronic word of mouth, online store belief's, persepsi harga dan motivasi belanja hedonis terhadap variabel terikat yaitu pembelian impulsif secara parsial.

\section{Tabel 1}

Uji T

Coefficientsa

\begin{tabular}{|c|c|c|c|c|c|c|}
\hline \multirow{2}{*}{\multicolumn{2}{|c|}{ Model }} & \multicolumn{2}{|c|}{ Unstandardized Coefficients } & \multirow{2}{*}{$\begin{array}{c}\text { Standardized } \\
\text { Coefficients } \\
\text { Beta }\end{array}$} & \multirow[b]{2}{*}{$\mathrm{t}$} & \multirow[b]{2}{*}{ Sig. } \\
\hline & & $\mathrm{B}$ & Std. Error & & & \\
\hline \multirow[t]{7}{*}{1} & (Constant) & -4.686 & 1.921 & & -2.439 & .015 \\
\hline & Total Promosi & .113 & .091 & .065 & 1.239 & .216 \\
\hline & Total Kualitas Informasi & .001 & .078 & .000 & .008 & .994 \\
\hline & Total E-WOM & -.006 & .117 & -.003 & -.051 & .959 \\
\hline & Total Online Store Belief's & .026 & .092 & .016 & .281 & .779 \\
\hline & Total Persepsi Harga & .218 & .099 & .132 & 2.217 & .027 \\
\hline & $\begin{array}{l}\text { Total Motivasi Belanja } \\
\text { Hedonis }\end{array}$ & .633 & .063 & .547 & 10.045 & .000 \\
\hline
\end{tabular}


Coefficientsa

\begin{tabular}{|c|c|c|c|c|c|c|}
\hline \multirow{2}{*}{\multicolumn{2}{|c|}{ Model }} & \multicolumn{2}{|c|}{ Unstandardized Coefficients } & \multirow{2}{*}{$\begin{array}{c}\begin{array}{c}\text { Standardized } \\
\text { Coefficients }\end{array} \\
\text { Beta }\end{array}$} & \multirow[b]{2}{*}{$\mathrm{t}$} & \multirow[b]{2}{*}{ Sig. } \\
\hline & & $\mathrm{B}$ & Std. Error & & & \\
\hline \multirow[t]{8}{*}{1} & (Constant) & -4.686 & 1.921 & & -2.439 & .015 \\
\hline & Total Promosi & .113 & .091 & .065 & 1.239 & .216 \\
\hline & Total Kualitas Informasi & .001 & .078 & .000 & .008 & .994 \\
\hline & Total E-WOM & -.006 & .117 & -.003 & -.051 & .959 \\
\hline & Total Online Store Belief's & .026 & .092 & .016 & .281 & .779 \\
\hline & Total Persepsi Harga & .218 & .099 & .132 & 2.217 & .027 \\
\hline & Total Motivasi Belanja & .633 & .063 & .547 & 10.045 & .000 \\
\hline & Hedonis & & & & & \\
\hline
\end{tabular}

a. Dependent Variable: Total Pembelian Impulsif

Kriteria hipotesis pada penelitian pengujian ini dilakukan dengan cara perbandingan, yaitu jika nilai signifikansi $<0,05$ dan jika thitung > tabel maka $\mathrm{H}_{0}$ ditolak, dan $\mathrm{H}_{1}$ diterima. Nilai $\mathrm{T}$ tabel pada distribusi $\mathrm{T}$ dihasilkan dengan nilai degrees of freedom melalui perhitungan $\mathrm{n}-\mathrm{k}(290-5=285)$, sehingga diperoleh nilai $\mathrm{T}$ tabel sebesar 1.968

Hipotesis dalam Uji T ini ialah sebagai berikut :

1) Hipotesis Promosi

Dari tabel 1, nilai $\mathrm{t}$ - hitung dari variabel promosi ialah $1,239<1,968$ dengan nilai p-value (Sig.) sebesar 0,216 >0,05. Sehingga $\mathrm{H}_{1}$ ditolak, dan $\mathrm{H}_{0}$ diterima, yang berarti promosi tidak berpengaruh secara signifikan terhadap pembelian impulsif. Hal ini menunjukkan bahwa perilaku pengguna Shoppe tidak terpengaruh oleh promosi dalam melakukan pembelian secara impulsif.

2) Hipotesis Kualitas Informasi

Dari tabel 1, nilai $\mathrm{t}$ - hitung dari variabel kualitas informasi ialah 0,008 $<1,968$ dengan nilai $p$-value (Sig.) sebesar 0,994 > 0,05. Sehingga $\mathrm{H}_{1}$ ditolak dan $\mathrm{H}_{0}$ diterima, yang berarti kualitas informasi tidak berpengaruh secara signifikan terhadap pembelian impulsif. Kualitas informasi saat ini tidak menjadi hal yang utama dalam menentukan sikap pembelian impulsif, karena kegiatan berbelanja yang dilakukan secara impulsif tidak terlalu mementingkan kualitas informasi yang disediakan pihak Shopee.

3) Hipotesis Electronic Word of Mouth

Dari tabel 1, nilai $\mathrm{t}$ - hitung dari variabel electronic word of mouth ialah $|-0,051|<$ 1,968 dengan nilai p-value (Sig.) sebesar 0,959 > 0,05. Sehingga $\mathrm{H}_{1}$ ditolak dan $\mathrm{H}_{0}$ diterima, yang berarti electronic word of mouth tidak berpengaruh secara signifikan terhadap pembelian impulsif. Electronic word of mouth saat ini tidak menjadi hal yang utama dalam menentukan sikap pembelian impulsif, karena kegiatan berbelanja yang dilakukan secara impulsif cenderung dilakukan secara tiba - tiba tanpa memlihat ulasan produk terlebih dahulu.

4) Hipotesis Online Store Belief's

Dari tabel 1, nilai t - hitung dari variabel online store belief's ialah 0,281 < 1,968 dengan nilai p-value (Sig.) sebesar 0,779 > 0,05. Sehingga $\mathrm{H}_{1}$ ditolak dan $\mathrm{H}_{0}$ diterima, yang berarti online store belief's tidak berpengaruh secara signifikan terhadap 
pembelian impulsif. Online store belief's saat ini tidak menjadi hal yang utama dalam menentukan sikap pembelian impulsif, karena pembelian impulsif cenderung tidak memperhatikan kepercayaan seseorang terhadap suatu toko online.

5) Hipotesis Persepsi Harga

Dari tabel 1 , nilai $\mathrm{t}$ - hitung dari variabel persepsi harga ialah 2,217 >1,968 dengan nilai p-value (Sig.) sebesar $0,027<0,05$. Sehingga $\mathrm{H}_{1}$ diterima dan $\mathrm{H}_{0}$ ditolak, yang berarti persepsi harga berpengaruh secara signifikan terhadap pembelian impulsif. Hal ini menunjukkan bahwa perilaku pengguna Shoppe dipengaruhi oleh persepsi harga dalam melakukan pembelian secara impulsif.

6) Hipotesis Motivasi Belanja Hedonis

Dari tabel 1, nilai $\mathrm{t}$ - hitung dari variabel motivasi belanja hedonis ialah 10,045 > 1,9722 dengan nilai $p$-value (Sig.) sebesar $0,000<0,05$. Sehingga $\mathrm{H}_{1}$ diterima dan $\mathrm{H}_{0}$ ditolak, yang berarti motivasi belanja hedonis berpengaruh secara signifikan terhadap pembelian impulsif. Motivas belanja hedonis cenderung tidak memedulikan faktor lain dalam berbelanja namun hanya memedulikan kepuasan setelah berbelanja sehingga mendukung terjadinya pembelian impulsif. Koefisien regresi motivas belanja hedonis juga menunjukkan angka yang paling besar, sehingga dapat disimpulkan bahwa faktor pendorong terbesar pengguna Shoppe untuk melakukan pembelian secara spontan adalah motivasi untuk mencapai kepuasan belanja.

b. Uji F (Uji Simultan)

Uji $\mathrm{F}$ perlu dilakukan karena Uji $\mathrm{F}$ digunakan guna menganalisis seberapa besar pengaruh variabel bebas promosi, kualitas informasi, electronic word of mouth, online store belief's, persepsi harga, dan motivasi belanja hedonis secara bersama-sama terhadap variabel terikat pembelian impulsif pengguna.

Tabel 2

Uji F

ANOVA

\begin{tabular}{|ll|r|r|r|r|r|}
\hline \multicolumn{1}{|l|}{} & Sudel of Squares & df & Mean Square & F & Sig. \\
\hline 1 & Regression & 1114.124 & 6 & 185.687 & 36.420 & $.000 \mathrm{a}$ \\
& Residual & 1442.856 & 283 & 5.098 & & \\
& 2556.979 & 289 & & & \\
\hline
\end{tabular}

a. Predictors: (Constant), Total_MotivasiBelanjaHedonis, Total_ElectronicWordofMouth,

Total_OnlineStoreBelief's, Total_Promosi, Total_KualitasInformasi, Total_PersepsiHarga

b. Dependent Variable: Total_PembeianImpulsif

Nilai $\mathrm{F}$ tabel pada distribusi $\mathrm{F}$ dihasilkan dengan memperhatikan nilai $\mathrm{k}$ (jumlah variabel keseluruhan adalah 7) dan nilai n (jumlah sampel adalah 323). Nilai degrees of freedom 1 (df 1$)$ didapatkan melalui perhitungan k-1 $(7-1=6)$. Nilai degrees of freedom 2 (df 2) didapatkan melalui perhitungan $\mathrm{n}-\mathrm{k}(290-6=284)$, sehingga didapatkan nilai $\mathrm{F}$ tabel sebesar 2.131

Hipotesis dalam Uji F ini ialah sebagai berikut :

Dari tabel 2, nilai $\mathrm{f}$ - hitung ialah $36,420>2,13$ nilai $\mathrm{f}$ - tabel dengan nilai $p$-value (Sig.) sebesar 0,000<0,05. Sehingga H0 ditolak dan H1 diterima, yang berarti ada pengaruh promosi, kualitas informasi, electronic word of mouth, online store belief's, 
persepsi harga, dan motivasi belanja hedonis secara bersama-sama terhadap pembelian impulsif.

c. Uji T (Parsial) Responden Pria

Tabel 3

Uji T Responden Pria

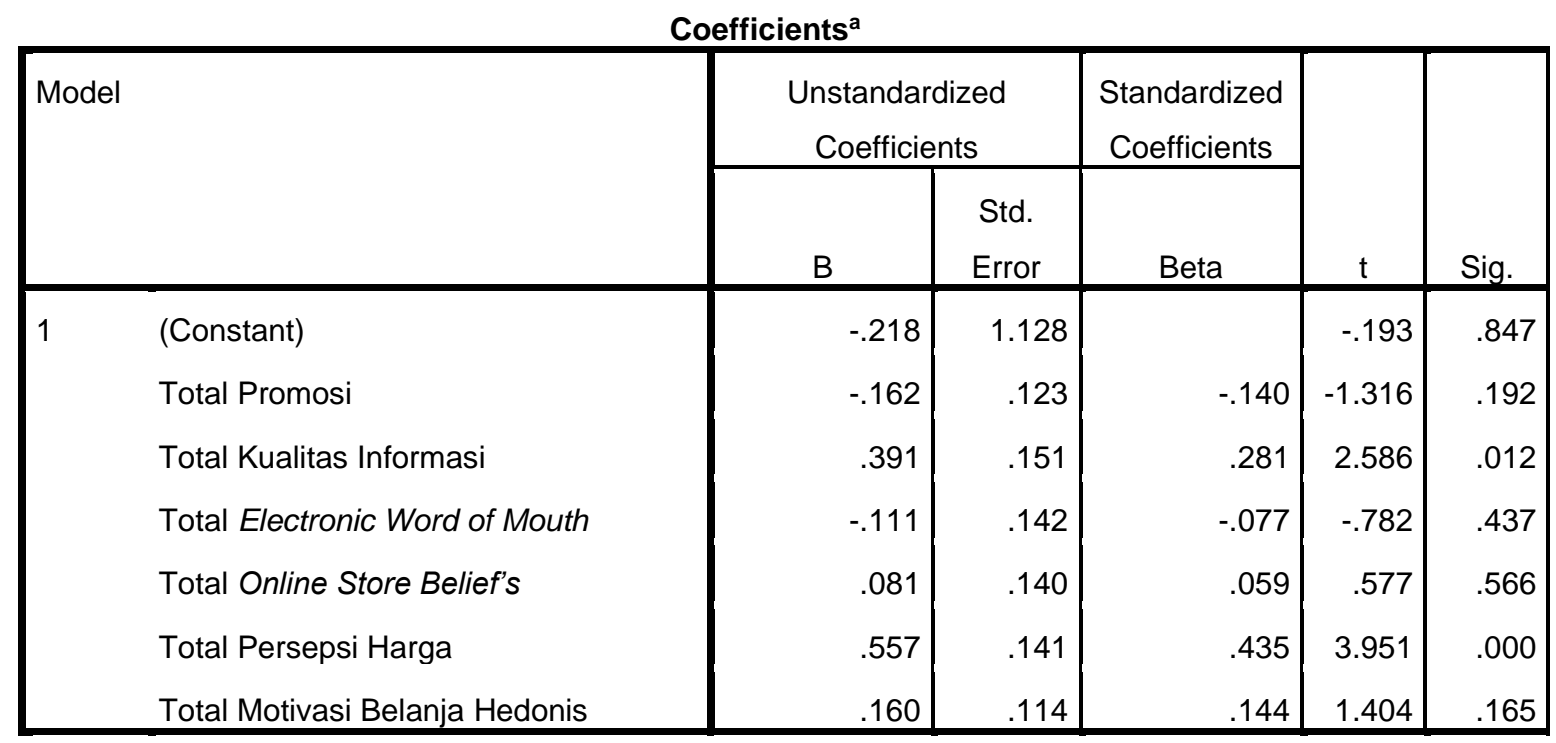

a. Dependent Variable: Total Pembelian Impulsif

Nilai $\mathrm{T}$ tabel pada distribusi $\mathrm{T}$ dihasilkan dengan memperhatikan nilai $\mathrm{k}$ (jumlah variabel keseluruhan adalah 7) dan nilai n (jumlah sampel adalah 79). Nilai degrees of freedom diperoleh melalui perhitungan $\mathrm{n}-\mathrm{k}(79-7=72)$, sehingga diperoleh nilai $\mathrm{T}$ tabel sebesar 1,993. Hipotesis dalam Uji T ini ialah sebagai berikut :

1) Hipotesis Promosi

Dari tabel 3, nilai $\mathrm{t}$ - hitung dari variabel promosi ialah $|-1,316|<1,993$ dengan nilai p-value (Sig.) sebesar 0,192 > 0,05. Sehingga $\mathrm{H}_{1}$ ditolak, dan $\mathrm{H}_{0}$ diterima, yang berarti promosi tidak berpengaruh secara signifikan terhadap pembelian impulsif.

2) Hipotesis Kualitas Informasi

Dari tabel 3, nilai $\mathrm{t}$ - hitung dari variabel kualitas informasi ialah 2,586 > 1,993 dengan nilai $p$-value (Sig.) sebesar $0,012<0,05$. Sehingga $\mathrm{H}_{0}$ ditolak dan $\mathrm{H}_{1}$ diterima, yang berarti kualitas informasi berpengaruh secara signifikan terhadap pembelian impulsif pria.

3) Hipotesis electronic word of mouth

Dari tabel 3, nilai $\mathrm{t}$ - hitung dari variabel electronic word of mouth ialah $|-0,782|<$ 1,993 dengan nilai p-value (Sig.) sebesar 0,437 > 0,05. Sehingga $\mathrm{H}_{1}$ ditolak dan $\mathrm{H}_{0}$ diterima, yang berarti electronic word of mouth tidak berpengaruh secara signifikan terhadap pembelian impulsif.

4) Hipotesis online store belief's

Dari tabel 3,33 nilai t - hitung dari variabel online store belief's ialah 0,577 < 1,993 dengan nilai p-value (Sig.) sebesar 0,566 > 0,05. Sehingga $\mathrm{H}_{1}$ ditolak dan $\mathrm{H}_{0}$ diterima, yang berarti online store belief's tidak berpengaruh secara signifikan terhadap pembelian impulsif.

5) Hipotesis Persepsi Harga 
Dari tabel 3, nilai $\mathrm{t}$ - hitung dari variabel persepsi harga ialah 3,951 > 1,993 dengan nilai $p$-value (Sig.) sebesar $0,000<0,05$. Sehingga $\mathrm{H}_{1}$ diterima dan $\mathrm{H}_{0}$ ditolak, yang berarti persepsi harga berpengaruh secara signifikan terhadap pembelian impulsif.

6) Hipotesis Motivasi Belanja Hedonis

Dari tabel 3, nilai $\mathrm{t}$ - hitung dari variabel motivasi belanja hedonis ialah 1,404 < 1,993 dengan nilai $p$-value (Sig.) sebesar $0,165>0,05$. Sehingga $\mathrm{H}_{1}$ diterima dan $\mathrm{H}_{0}$ ditolak, yang berarti motivasi belanja hedonis tidak berpengaruh secara signifikan terhadap pembelian impulsif.

d. Uji T (Parsial) Responden Wanita

\section{Tabel 4}

\section{Uji T Responden Wanita}

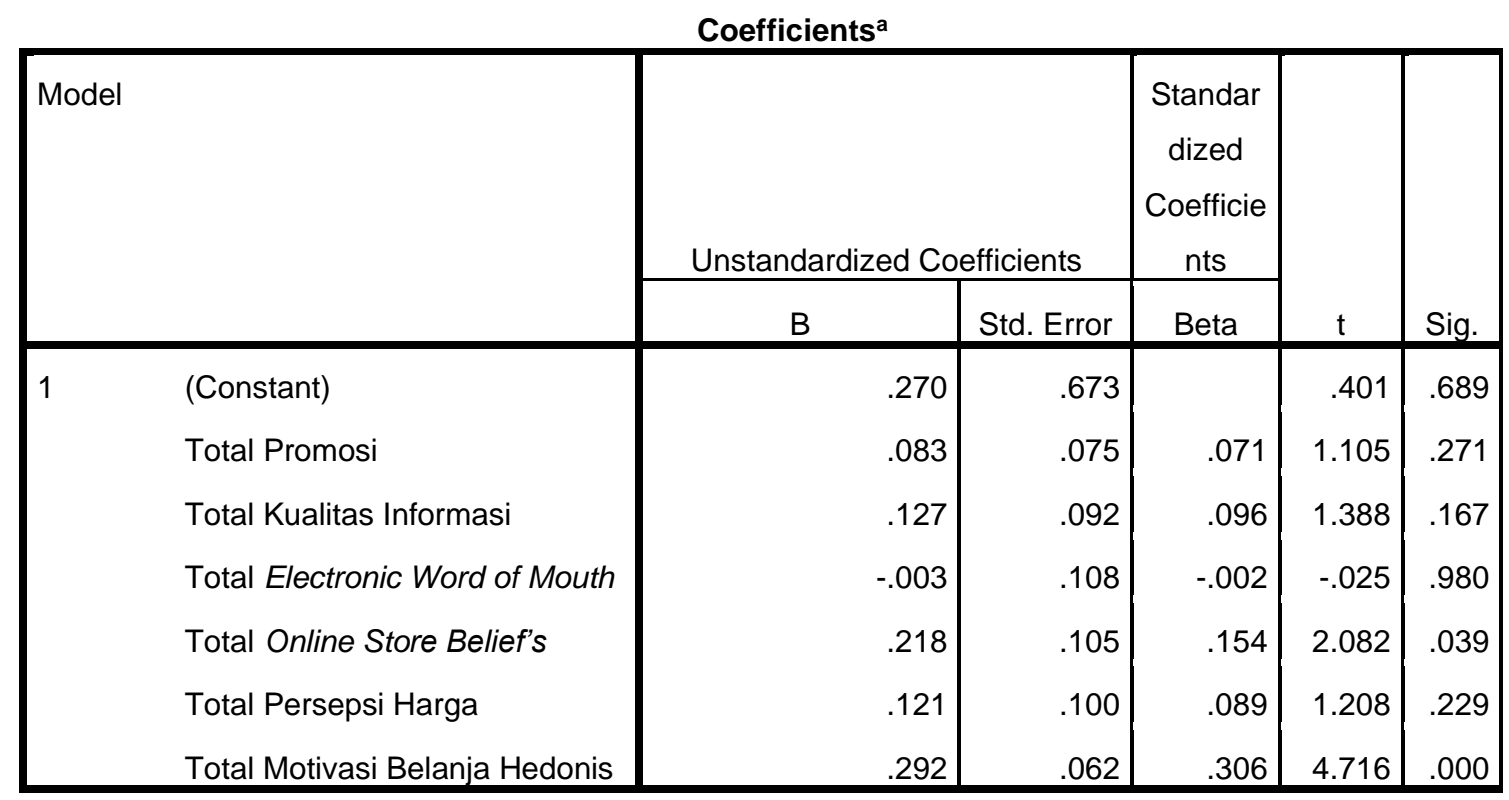

a. Dependent Variable: Total Pembelian Impulsif

Nilai $\mathrm{T}$ tabel pada distribusi $\mathrm{T}$ dihasilkan dengan memperhatikan nilai $\mathrm{k}$ (jumlah variabel keseluruhan adalah 7) dan nilai n (jumlah sampel adalah 211). Nilai degrees of freedom diperoleh melalui perhitungan $\mathrm{n}-\mathrm{k}(211-7=204)$, sehingga diperoleh nilai $\mathrm{T}$ tabel sebesar 1,972. Hipotesis dalam Uji T ini ialah sebagai berikut :

1) Hipotesis Promosi

Dari tabel 4, nilai $\mathrm{t}$ - hitung dari variabel promosi ialah $1,105<1,972$ dengan nilai p-value (Sig.) sebesar 0,271 >0,05. Sehingga $\mathrm{H}_{1}$ ditolak, dan $\mathrm{H}_{0}$ diterima, yang berarti promosi tidak berpengaruh secara signifikan terhadap pembelian impulsif.

2) Hipotesis Kualitas Informasi

Dari tabel 4, nilai t - hitung dari variabel kualitas informasi ialah 1,388 < 1,972 dengan nilai $p$-value (Sig.) sebesar 0,167>0,05. Sehingga $\mathrm{H}_{1}$ ditolak dan $\mathrm{H}_{0}$ diterima, yang berarti kualitas informasi tidak berpengaruh secara signifikan terhadap pembelian impulsif.

3) Hipotesis electronic word of mouth

Dari tabel 4, nilai $\mathrm{t}$ - hitung dari variabel electronic word of mouth ialah $|-0,025|<$ 1,972 dengan nilai p-value (Sig.) sebesar 0,980 > 0,05. Sehingga $\mathrm{H}_{1}$ ditolak dan $\mathrm{H}_{0}$ diterima, yang berarti electronic word of mouth tidak berpengaruh secara signifikan terhadap pembelian impulsif. 
4) Hipotesis online store belief's

Dari tabel 4,34 nilai t - hitung dari variabel online store belief's ialah 2,082 > 1,972 dengan nilai p-value (Sig.) sebesar $0,039<0,05$. Sehingga $\mathrm{H}_{0}$ ditolak dan $\mathrm{H}_{1}$ diterima, yang berarti online store belief's berpengaruh secara signifikan terhadap pembelian impulsif.

5) Hipotesis Persepsi Harga

Dari tabel 4, nilai $\mathrm{t}$ - hitung dari variabel persepsi harga ialah 1,208 $<1,972$ dengan nilai $p$-value (Sig.) sebesar 0,229 >0,05. Sehingga $\mathrm{H}_{0}$ diterima dan $\mathrm{H}_{1}$ ditolak, yang berarti persepsi harga tidak berpengaruh secara signifikan terhadap pembelian impulsif.

6) Hipotesis Motivasi elanja Hedonis

Dari tabel 4, nilai $\mathrm{t}$ - hitung dari variabel motivasi belanja hedonis ialah 4,716 > 1,972 dengan nilai $p$-value (Sig.) sebesar $0,000<0,05$. Sehingga $\mathrm{H}_{1}$ diterima dan $\mathrm{H}_{0}$ ditolak, yang berarti motivasi belanja hedonis berpengaruh secara signifikan terhadap pembelian impulsif.

Menurut hasi uji T diatas, dapat diketahui bahwa kualitas informasi dan persepsi harga berpengaruh secara signifikan terhadap pembelian impulsif pada gender pria. Sedangkan online store belief's dan motivasi belanja hedonis berpengaruh secara signifikan terhadap pembelian impulsif pada gender wanita. Hal ini menunjukan adanya perbedaan perilaku terhadap pembelian impulsif pada gender pria dan wanita.

\section{Kesimpulan}

Pada penelitian ini membahas mengenai analisis pengaruh promosi, kualitas informasi, electronic word of mouth, online sotre belief's, persepsi harga, dan motivasi belanja hedonis terhadap pembelian impulsif pengguna aplikasi Shopee dengan gender sebagai pemoderasi. Data yang diperoleh dengan menyebarkan kuesioner melalui Google Form dengan menggunakan teknik sampling purposive yakni teknik pengambilan sampel dengan pertimbangan tertentu. Pengambilan sampel dilakukan pada responden yang pernah menggunakan aplikasi Shopee. Setelah dilakukannya penelitian mengenai analisis pengaruh promosi, kualitas informasi, electronic word of mouth, online sotre belief's, persepsi harga, dan motivasi belanja hedonis terhadap pembelian impulsif pengguna aplikasi Shopee dan melaksanakan uji - uji statistik dengan menggunakan SPSS 18 maka dapat diambil kesimpulan sebagai berikut :

a. Variabel promosi secara parsial (individu) tidak berpengaruh secara signifikan terhadap pembelian impulsif.

b. Variabel kualitas informasi secara parsial (individu) tidak berpengaruh secara signifikan terhadap pembelian impulsif.

c. Variabel kualitas electronic word of mouth secara parsial (individu) tidak berpengaruh signifikan terhadap pembelain impulsif.

d. Variabel kualitas online store belief's secara parsial (individu) tidak berpengaruh signifikan terhadap pembelain impulsif.

e. Variabel persepsi harga secara parsial (individu) berpengaruh secara signifikan terhadap pembelian impulsif.

f. Variabel motivasi belanja hedonis secara parsial (individu) berpengaruh secara signifikan terhadap pembelian impulsif.

g. Variabel promosi, kualitas informasi, electronic word of mouth, online store belief's, persepsi harga, dan motivasi belanja hedonis berpengaruh secara bersamasama terhadap pembelian impulsif.

Variabel online store belief's dan persepsi harga secara parsial berpengaruh secara signifikan terhadap pembelian impulsif pada gender wanita. Sedangkan variabel kualitas 
informasi dan motivasi belanja hedonis secara parsial berpengaruh secara signifikan terhadap pembelian impulsif pada gender pria.

Berdasarkan pengujian dan juga kesimpulan mengenai pengaruh variabel promosi, kualitas informasi, electronic word of mouth, online store belief's, persepsi harga, dan motivasi belanja terhadap pembelian impulsif pengguna aplikasi Shopee, maka peneliti memberikan saran kepada perusahaan Shopee dengan mempertimbangkan empat hal dalam penelitian ini yaitu persepsi harga dan motivasi belanja hedonis karena variabel ini berpengaruh terhadap pembelian impulsif pada aplikas Shopee sebagai berikut :

a. Perhatikan strategi yang tepat untuk meningkatkan pembelian impulsif pada aplikasi Shopee berdasarkan gender pria dan wanita dengan mempertimbangkan variabel kualitas informasi dan persepsi harga untuk meningkatkan pembelian impulsif untuk gender pria. Perusahaan Shopee dapat mempertimbangkan variabel online store belief's dan motivasi belanja hedonis untuk meningkatkan pembelian impulsif pada gender wanita.

b. Apabila akan melakukan penelitian lebih lanjut mengenai electronic word of mouth terhadap pembelian impulsif, peneliti menyarankan untuk menggunakan indikator lain untuk mengukur electronic word of mouth seperti pemasaran dari mulut ke mulut melalui social media yang berpotensi menyebar dengan luas dan cepat.

c. Pada penelitian ini sebanyak $57,6 \%$ pembelian impulsif Shopee dipengaruhi oleh variabel - variabel lain yang memengaruhi pembelian impulsif Shopee seperti loyalitas pengguna, persepsi kemudahan, pengalaman pengguna dan lain sebagainya.

\section{DAFTAR PUSTAKA}

[1] Fachruddin, Andi. 2016. Manajemen Pertelevisian Modern. Yogyakarta : Penerbit CV. Andi Offset.

[2] Handayani, Fitri. 2020. Pengaruh Atmosfer Toko Terhadap Pembelian. Bandung : Penerbit Hamdan Media Umat.

[3] Indrasari, Meithiana. 2019. Pemasaran dan Kepuasan Pelanggan. Surabaya : Penerbit Unitomo Press

[4] Kusumowidagdo, Astrid. 2013. Desain Ritel. Jakarta : Penerbit Gramedia Pustaka Utama.

[5] Mulyani, Sri. 2018. Sistem Informasi Akuntansi: Aplikasi Di Sektor Publik. Bandung : Penerbit Unpad Press.

[6] Rathore, Sumangla, dan Avinash Panwar. 2016. Capturing, Analyzing, and Managing

[7] Sari, Dian Cita, Faried Effendy, dan Andriasan Sudarso. 2020. Perdagangan Elektronik: Berjualan di Internet. Penerbit : Yayasan Kita Menulis.

[8] Sugiyono. 2015. Metode Penelitian Pendidikan (Pendekatan Kuantitatif, Kualitatif, Dan R\&D). Bandung : Penerbit Alfabeta 